\title{
Effect of Telemetric Interventions on Glycated Hemoglobin A1c and Management of Type 2 Diabetes Mellitus: Systematic Meta-Review
}

\author{
Claudia Eberle, MD, Prof Dr; Stefanie Stichling, MSc

\section{Corresponding Author:} \\ Claudia Eberle, MD, Prof Dr \\ Medicine with Specialization in Internal Medicine and General Medicine \\ Hochschule Fulda-University of Applied Sciences \\ Leipziger Strasse 123 \\ Fulda, 36037 \\ Germany \\ Phone: 496619640 ext 6328 \\ Fax: 496619640649 \\ Email: claudia.eberle@hs-fulda.de
}

Medicine with Specialization in Internal Medicine and General Medicine, Hochschule Fulda-University of Applied Sciences, Fulda, Germany

\section{Abstract}

Background: Diabetes mellitus is a chronic burden, with a prevalence that is increasing worldwide. Telemetric interventions have attracted great interest and may provide effective new therapeutic approaches for improving type 2 diabetes mellitus (T2DM) care.

Objective: The objective of this study was to analyze the clinical effectiveness of telemetric interventions on glycated hemoglobin $\mathrm{A}_{1 \mathrm{c}}\left(\mathrm{HbA}_{1 \mathrm{c}}\right)$ specifically and T2DM management generally in a systematic meta-review.

Methods: A systematic literature search was performed in PubMed, CINAHL, Cochrane Library, Web of Science Core Collection, and EMBASE databases from January 2008 to April 2020. Studies that addressed $\mathrm{HbA}_{1 \mathrm{c}}$, blood pressure, fasting blood glucose, BMI, diabetes-related and health-related quality of life, cost-effectiveness, time savings, and the clinical effectiveness of telemetric interventions were analyzed. In total, 73 randomized controlled trials (RCTs), 10 systematic reviews/meta-analyses, 9 qualitative studies, 2 cohort studies, 2 nonrandomized controlled studies, 2 observational studies, and 1 noncontrolled intervention study were analyzed.

Results: Overall, 1647 citations were identified. After careful screening, 99 studies ( $\mathrm{n}=15,939$ patients; $\mathrm{n}=82,436$ patient cases) were selected by two independent reviewers for inclusion in the review. Telemetric interventions were categorized according to communication channels to health care providers: (1) "real-time video" interventions, (2) "real-time audio" interventions, (3) "asynchronous" interventions, and (4) "combined" interventions. To analyze changes in $\mathrm{HbA}_{1 \mathrm{c}}$, suitable RCTs were pooled and the average was determined. An $\mathrm{HbA}_{1 \mathrm{c}}$ decrease of $-1.15 \%$ (95\% CI $-1.84 \%$ to $-0.45 \%$ ), yielding an $\mathrm{HbA}$ c value of $6.95 \%$ (SD 0.495), was shown in studies using 6-month "real-time video" interventions.

Conclusions: Telemetric interventions clearly improve $\mathrm{HbA}_{1 \mathrm{c}}$ values in both the short term and the long term and contribute to the effective management of T2DM. More studies need to be done in greater detail.

(J Med Internet Res 2021;23(2):e23252) doi: 10.2196/23252

\section{KEYWORDS}

telemedicine; telemetry; diabetes

\section{Introduction}

Diabetes mellitus is a chronic burden, with a prevalence that is increasing worldwide [1]. In 2019, approximately 463 million adults were diagnosed with diabetes [1]. By 2045, the
International Diabetes Federation (IDF) projects an increase of $51 \%$ up to approximately 700 million people diagnosed with diabetes [1]. The IDF also estimates that one-half of individuals living with diabetes are undiagnosed [1]. According to the American Diabetes Association, type 2 diabetes mellitus 
(T2DM) is the most prevalent type of diabetes and represents approximately $90 \%$ to $95 \%$ of all diabetes cases [2]. Common risk factors that appear to lead to T2DM are increasing age, increasing BMI, and lack of physical activity [2]. From a pathophysiological perspective, T2DM emerges mainly because of the progressive loss of beta-cell insulin secretion due to insulin resistance. Typically, however, relative insulin deficiency, as well as central and peripheral insulin resistance, arises [2].

T2DM is closely associated with diabetic microvascular complications-such as nephropathy, retinopathy, and neuropathy [3] —and macrovascular complications—-such as coronary heart disease, stroke, and peripheral artery disease [4], as well as other comorbidities and general complications. In addition, cardiovascular disease is the main cause of death in patients with T2DM [4].

Therefore, optimal glycemic management is crucial [3]. Recent studies have reported positive effects of telemetric interventions on diabetes management [5,6]. Telemetry, defined as "a mode of delivering healthcare services through the use of telecommunications technologies, including but not limited to asynchronous and synchronous technology, and remote patient monitoring technology, by a healthcare practitioner to a patient or a practitioner at a different physical location than the healthcare practitioner" [7], may be a promising approach to improve the clinical effectiveness of T2DM management. This digital field of application is constantly evolving and expanding [8]. Telematics, the science of telecommunication and informatics, developed in the 1970s, and telemedicine emerged as a part of telematics in the 1970s and 1980s [8]. For a long time, the physical distance between the user groups was the dominant characteristic of telemedicine. The emergence of the internet in the 1990s opened up new communication channels. As a result, the focus was no longer on distance but on the fundamental application of technologies to overcome distance [8]. Electronic health (eHealth), characterized as health management based on electronic systems and communication, emerged from this idea [8]. The new concept of digital health combines the digital and genomic-proteomic revolutions with health care and everyday life [8].

In this systematic meta-review [9], we focused on telemetric communication pathways between health care professionals and patients. We aimed to update the evidence for and clinical effectiveness of telemetric approaches in the context of T2DM management considering different study designs such as randomized controlled trials (RCTs), clinical trials (CTs), systematic reviews (SRs), and meta-analyses (MAs). Furthermore, we focused on main clinical outcomes, such as glycated hemoglobin $\mathrm{A}_{1 \mathrm{c}}\left(\mathrm{Hb}_{1 \mathrm{c}}\right)$, blood pressure (BP), fasting blood glucose (FBG), BMI, diabetes-related quality of life (DRQoL), and health-related quality of life (HRQoL), as well as the cost-effectiveness, time savings, and clinical effectiveness of telemetric interventions in general. $\mathrm{HbA}_{1 \mathrm{c}}$ is one of the major clinical parameters in T2DM and therefore our main focus.

To our knowledge, this study is the first and only systematic meta-review of telemetric interventions in T2DM management with respect to the following special features: we developed and applied a unique classification system for analyzing telemetric interventions and provide detailed insights by including several study designs and a wide range of clinical outcomes.

\section{Research Design and Methods}

\section{Search Strategy}

A systematic search was conducted targeting the period between January 2008 and April 2020. No protocol has been published. Keywords (diabetes mellitus, telemetry, telemonitoring, and telemedicine) were selected from the MEDLINE Medical Subject Headings and EMBASE Subject Headings databases and searched in titles/abstracts (Multimedia Appendix 1). In general, the steps were as follows: (1) search in five relevant databases, (2) eliminate duplicates, (3) screen titles and abstracts, (4) assess peer-reviewed publications for eligibility, (5) perform additive research via reference lists, (6) select T2DM studies, (7) extract relevant data, and (8) classify the publications.

\section{Study Selection}

Publications addressing telemetric interventions targeting T2DM management were included.

Telemetry was defined as "a mode of delivering healthcare services through the use of telecommunications technologies, including but not limited to asynchronous and synchronous technology, and remote patient monitoring technology, by a healthcare practitioner to a patient or a practitioner at a different physical location than the healthcare practitioner" [7]. We included video consultations, telephone counselling, asynchronous communication by email, SMS text messaging, internet/web-based platforms, and mixed forms.

Studies were screened and selected by two independent reviewers. Disagreements were resolved by a consensus-based discussion. We selected studies that met the following inclusion criteria: (1) peer-reviewed articles and studies; (2) written in English or German; (3) study design was an SR, MA, CT, or RCT; and (4) included interventions that involved direct interaction between patients and health care professionals through feedback and data transmission. We also considered quantitative and qualitative studies.

Smartphone/mobile app-based interventions were excluded and analyzed separately in another publication. We also rejected publications that observed mixed populations (eg, pooled patients with T1DM and T2DM), provided pooled data with other digital applications, addressed prevention or diagnosis, or focused on the presentation of technologies. Multimedia Appendix 2 shows the PRISMA (Preferred Reporting Items for Systematic Reviews and Meta-Analyses) flow diagram.

\section{Data Extraction}

Year of publication, location of the study, duration of the intervention, study design, sample sizes, intervention and control groups used, frequency of contact, feedback methods, outcomes, effects, statistical significance, and conclusions were extracted from each publication (step 7). 


\section{Study Classification and Analysis}

For analysis, the interventions were classified a priori (step 8) based on the technologies used, study design, and outcomes (Figure 1).

Figure 1. Study classification procedure. BP: blood pressure; DRQoL: disease-related quality of life; FBG: fasting blood glucose; HbA $1 \mathrm{c}$ : glycated hemoglobin A1c; HRQoL: health-related quality of life; MA: meta-analysis; RCT: randomized controlled trial; SR: systematic review.
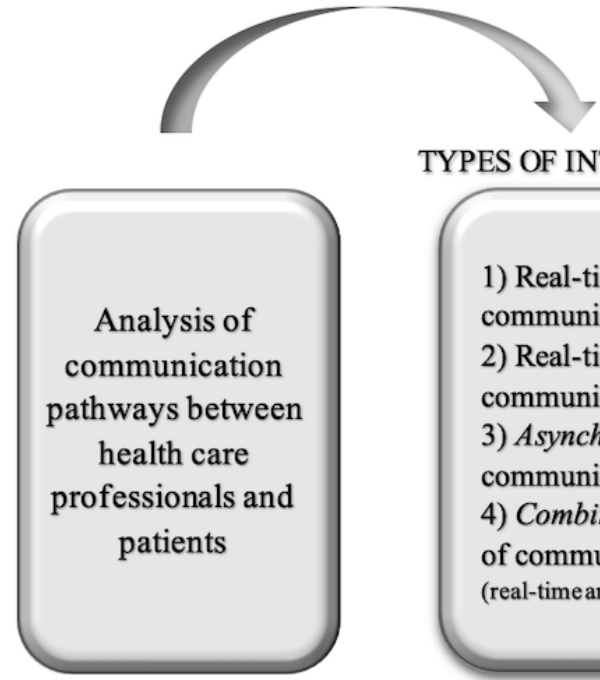
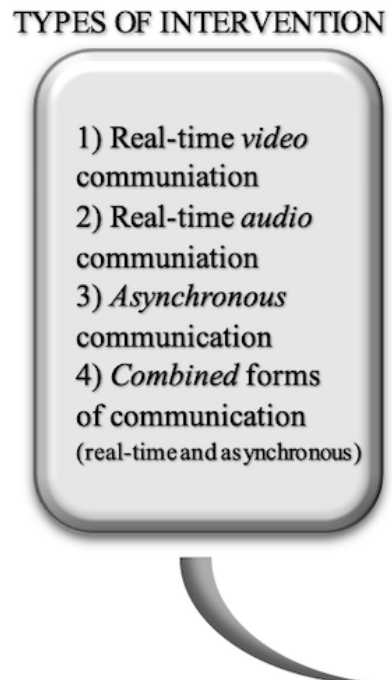

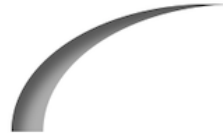

STUDY DESIGNS

1) SR and MA

2) $\mathrm{RCT}$

3) Cohort study

4) Qualitative study

5) Nonrandomized controlled trial

6) Observational study

7) Noncontrolled

intervention study

\section{MAIN CLINICAL OUTCOMES}
1) $\mathrm{HbA}_{1 \mathrm{c}}$
2) $\mathrm{BP}$
3) Body weight
4) FBG
5) BMI
6) $\mathrm{DRQoL}$
7) HRQoL
8) Cost-effectiveness
9) Time savings

- "Real-time video" interventions (12 intervention studies): synchronous, face-to-face communication by videoconferencing and video consulting.

- "Real-time audio" interventions (17 intervention studies): synchronous communication by telephone calls (telephone coaching and counselling).

- "Asynchronous" interventions (28 intervention studies): asynchronous communication by email, SMS text messaging, internet/web-based platforms, server, home gateway, and post.

- "Combined" interventions (33 intervention studies): interventions involving real-time (ie, synchronous) and asynchronous communication, with a subgroup of "video clips" (interventions providing educational videos).

We conducted a small subgroup MA to assess whether the impact of the four intervention types, as well as the short- and long-term effects on the management of $\mathrm{HbA}_{1 \mathrm{c}}$ concentrations, differed. To determine the change in $\mathrm{HbA}_{1 \mathrm{c}}$, we pooled appropriate RCTs and calculated the differences in means and 95\% CIs for the intervention and control groups at the study end points. RCTs in which the changes from baseline to the end of the study were reported as a percentage were included. Studies in which the control group received telemetric support were excluded. Mean deviations and SDs were extracted unchanged.

In addition, the publication bias was assessed visually as a funnel plot using $\mathrm{HbA}_{1 \mathrm{c}}$ values based on the RCTs and the mean differences (MDs) from our subgroup MA.

We also pooled the number of patients, specifically the number of unique patients as well as the number of patient cases related to the outcomes. In the former scenario, each patient occurred only once, addressing the number of individual patients (without SRs and MAs), and in the latter scenario, with a focus on specific outcomes, patient cases were analyzed based on the respective outcomes and thus may have been included several times (including SRs and MAs).

\section{Results}

\section{Description of Studies}

Our search strategy identified 1647 citations. After removing duplicates, 1116 studies were screened and 875 ineligible papers excluded. After assessing 241 studies with full text, 72 inappropriate studies were rejected. As an interim result, 189 studies were identified, of which 23 focused on type 1 diabetes mellitus, 99 focused on T2DM, 11 focused on gestational diabetes, and 51 focused on mixed populations. In this systematic meta-review, we included 99 suitable T2DM publications, analyzing 15,939 patients and 82,439 patient cases. A list of the included studies is provided in Multimedia Appendix 3.

Baseline characteristics of the studies are summarized in Table 1. Of the 99 studies, 10 were SRs and MAs, 73 were RCTs, 9 were qualitative examinations, 2 were cohort studies, 2 were non-RCTs, 2 were observational studies, and 1 was a noncontrolled intervention study. When classifying the studies according to location and type of intervention, SRs and MAs were excluded due to their heterogeneity, and thus 89 studies were taken into account. Of these 89 studies, 35 were done in the United States, 21 in Asia, 20 in Europe, 6 in Australia, 3 in Canada, 2 in Brazil, and 2 in Turkey.

In total, 12 "real-time video," 17 "real-time audio," 28 "asynchronous," 33 "combined," and 3 "video clip" 
interventions were classified. One study matched the classification criteria for two categories [10]. A detailed summary of all studies is shown in Multimedia Appendix 4.
A descriptive examination of the funnel plot created using $\mathrm{HbA}_{1 \mathrm{c}}$ values indicated a mild form of asymmetry (Multimedia Appendix 8).

Table 1. Baseline characteristics of reviewed studies.

\begin{tabular}{|c|c|}
\hline Studies & $\mathrm{n}(\%)$ \\
\hline \multicolumn{2}{|l|}{ All studies (N=99) } \\
\hline \multicolumn{2}{|l|}{ Study design } \\
\hline $\mathrm{SRs}^{\mathrm{a}}$ and MAs ${ }^{\mathrm{b}}$ & $10(10)$ \\
\hline Randomized controlled trials (total) & $73(74)$ \\
\hline Pilot studies & $3(3)$ \\
\hline Cohort studies & $2(2)$ \\
\hline Qualitative studies & $9(9)$ \\
\hline Nonrandomized controlled trials & $2(2)$ \\
\hline Observational studies & $2(2)$ \\
\hline Noncontrolled intervention studies & $1(1)$ \\
\hline \multicolumn{2}{|l|}{ Years } \\
\hline $2008-2011$ & $21(21)$ \\
\hline $2012-2014$ & $26(26)$ \\
\hline $2015-2017$ & $32(32)$ \\
\hline $2018-2020$ & $19(19)$ \\
\hline \multicolumn{2}{|l|}{ All studies, excluding SRs and MAs $(n=89)$} \\
\hline \multicolumn{2}{|l|}{ Location } \\
\hline United States & $35(39)$ \\
\hline Canada & $3(3)$ \\
\hline Brazil & $2(2)$ \\
\hline Europe & $20(23)$ \\
\hline Asia & $21(24)$ \\
\hline Australia & $6(7)$ \\
\hline Turkey & $2(2)$ \\
\hline \multicolumn{2}{|l|}{ Intervention } \\
\hline Real-time video & $12(14)$ \\
\hline Real-time audio & $17^{\mathrm{c}}(19)$ \\
\hline Asynchronous & $28^{\mathrm{c}}(32)$ \\
\hline Combined forms (total) & $33(37)$ \\
\hline "Video clips" subgroup & $3(3)$ \\
\hline
\end{tabular}

${ }^{\mathrm{a}} \mathrm{SRs}$ : systematic reviews.

${ }^{b}$ MAs: meta-analyses.

${ }^{\mathrm{c}}$ One study matched the criteria for two categories.

\section{Impact on Main Outcomes}

An overview of significant and not significant intervention effects on $\mathrm{HbA}_{1 \mathrm{c}}$, BP, FBG, BMI, DRQoL, HRQoL, cost-effectiveness, time savings, and clinical effectiveness is displayed in Multimedia Appendix 5. Multimedia Appendix 6 shows the significant effects on the main outcomes. Briefly, $85 \%$ (84/99) of the intervention studies found explicit beneficial effects due to telemetric interventions, depending on the outcomes studied (see Multimedia Appendix 4). 


\section{SRs and MAs (n=10)}

$H b A_{1 c}(n=8)$

All SRs and MAs reported clear decreases in $\mathrm{HbA}_{1 \mathrm{c}}$ values $(P<.05)$ by implementing telemetric interventions [5,11-17]. MAs $(5 / 5,100 \%)$ indicated that telemetry was significantly associated with an obvious improvement between $-0.37 \%$ and $-0.55 \%$ in $\mathrm{HbA}_{1 \mathrm{c}}$ values compared with the usual care $(P<.001$ [15], $P<.001$ [13], $P<.001$ [12], $P<.001$ [5], and $P<.05$ [10]).

\section{$\operatorname{BMI}(n=1)$}

According to Kim et al [5], telemonitoring was associated with a significantly reduced BMI (weighted $\mathrm{MD}=-0.25 \mathrm{~kg} / \mathrm{m}^{2}, 95 \%$ CI -0.49 to $-0.01, I^{2}=16.7 \%$ ) compared with usual care.

\section{Cost-Effectiveness $(n=1)$}

Due to the heterogeneous data situation, Zhai et al [13] could not draw any conclusions regarding cost-effectiveness.

\section{"Real-Time Video" Interventions (n=12)}

$\boldsymbol{H b A}_{\mathbf{l c}}(\boldsymbol{n}=\mathbf{9})$

Overall, $89 \%$ (8/9) of the studies reported a clear reduction in $\mathrm{HbA}_{1 \mathrm{c}}$ values. More specifically, five RCTs $(5 / 9,56 \%)$ indicated significant positive effects $(P=.022$ [18], $P=.004$ [19], $P=.023$ [20], $P<.05$ [21], and $P=.013$ [22]). For example, $\mathrm{HbA}_{1 \mathrm{c}}$ values declined significantly in an intervention group with weekly video conferences compared with a control group $(0.49 \%$ versus $0.17 \% ; P=.013$ ) [22].

\section{$\boldsymbol{F B G}(\boldsymbol{n}=3)$}

Overall, definite improvements regarding FBG were documented. Tavsanli et al [22] (weekly video conferences) and Rasmussen et al [20] (average 4.1 video consultations in 6 months) reported clearly lower FBG levels in the intervention group compared with control groups $(P>.05$ [22] and $P<.015$ [20]), whereas Hansen et al [18] provided monthly video conferences additional to usual care and reported no substantial changes in FBG levels in relation to the study (significance not reported).

\section{$\boldsymbol{B P}(\boldsymbol{n}=3)$}

In general, most RCTs observed no essential changes in systolic and diastolic BP measurements (intergroup P>.05 [20] and significance not reported [18]). However, a clear improvement in $\mathrm{BP}$ was seen in a 12-month videoconferencing intervention, as reported by Davis et al [19], although the effect was not significant compared with a control group (intervention systolic BP $130.8 \mathrm{mmHg}$, SD $3.6 \mathrm{mmHg}$, versus $127.6 \mathrm{mmHg}$, SD 4.0 $\mathrm{mmHg}, P=.76$; diastolic BP $72.7 \mathrm{mmHg}$, SD $2.1 \mathrm{mmHg}$, versus $70.2 \mathrm{mmHg}$, SD $2.2 \mathrm{mmHg}, P=.64)$.

\section{Body Weight (n=1)}

Rasmussen et al [20] showed a significantly higher weight loss with in-person clinic visits $(-1.7 \mathrm{~kg})$ compared with video consultations $(-0.6 \mathrm{~kg} ; P=.023)$.

\section{$B M I(n=2)$}

Hansen et al [18] found no obvious changes in terms of BMI, whereas Davis et al [19] indicated substantial improvements compared to usual care, although the finding was not significant $\left(30.6 \mathrm{~kg} / \mathrm{m}^{2}, \mathrm{SD} 1.4 \mathrm{~kg} / \mathrm{m}^{2}\right.$ versus $35.8 \mathrm{~kg} / \mathrm{m}^{2}, \mathrm{SD} 1.4 \mathrm{~kg} / \mathrm{m}^{2}$; $P=.73)$.

\section{HRQoL (n=1)}

Hansen et al [18] noted that significant changes in mental or physical health rankings were not detected.

\section{Time Savings $(n=1)$}

Gordon et al [23] revealed shorter travel times and less time in waiting rooms according to interviews with participants, although no statistical measurements were performed.

\section{Enablers and Barriers $(n=2)$}

Carlisle and Warren [24] suggested that consumer-friendly technologies and the integration of telemetry into everyday lives are important for the successful implementation of telemetry interventions.

\section{"Real-Time Audio" Interventions (n=17)}

$H b A_{1 c}(n=9)$

In summary, all studies showed precise improvements in $\mathrm{HbA}_{1 \mathrm{c}}$ levels with audio interventions in real time. Odnoletkova et al [25] and Walker et al [26] reported significant improvements in their intervention groups compared with matched control groups (intervention group: $-0.2 \%, 95 \% \mathrm{CI}-0.3$ to $-0.1, P=.003$ [25]; and intervention group versus control group: $-0.23 \%$ versus $0.13 \%, P=.04$ [26]). Sarayani et al [27], Trief et al [28], Maslakpak et al [29], Blackberry et al [30], Benson et al [31], and Vasconcelos et al [32] displayed clear, but not significant, improvements in $\mathrm{HbA}_{1 \mathrm{c}}$ levels compared with control groups $(P>.05)$. Notably, some control groups [27-29,31] received some forms of telemetric or even educational support. Interestingly, Walker et al [26] found that patients who completed at least six phone calls with a health educator over a 12-month period had significant reductions in their $\mathrm{HbA}_{1 \mathrm{c}}$ concentrations $(P<.05)$.

The RCT of McMahon et al [10] was classified in two categories ("real-time audio" and "asynchronous" interventions) because it involved the comparison of a telephone-based intervention with two "asynchronous" interventions. $\mathrm{HbA}_{1 \mathrm{c}}$ decreased at a rate of $0.32 \%$ every 3 months for the online arm, $0.36 \%$ for the telephone arm, and $0.41 \%$ for the web training arm (all $P<.001$ ).

\section{$F B G(n=2)$}

The "real-time audio" intervention studies showed obvious improvements in FBG. In the study by Varney et al [33], FBG levels clearly improved in subjects in the intervention group ( $8.9 \mathrm{mmol} / \mathrm{L}, 95 \%$ CI 8.0 to 9.7 , to $8.5 \mathrm{mmol} / \mathrm{L}, 95 \%$ CI 7.7 to 9.4) compared with those in the control group $(P=.02)$, but not in a long-term way, while Maslakpak et al [29] outlined distinct, but not significant, differences between telephone and control groups $(P=.766)$.

\section{$B P(n=3)$}

In general, all "real-time audio" intervention studies reported clear improvements in BP. Trief et al [28] showed a greater improvement in systolic BP in the "individual calls" group than 
in the "diabetes education" group at 8 months $(P=.021)$. Vasconcelos et al [32] reported improvements in systolic BP (130.25 mmHg to $125.87 \mathrm{mmHg} ; P=.171)$ and diastolic BP (72.12 $\mathrm{mmHg}$ to $71.12 \mathrm{mmHg} ; P=.640$ ). In addition, Varney et al [33] indicated significant improvements in diastolic BP within the telephone group ( $80 \mathrm{mmHg}, 95 \%$ CI 76 to 84 , to 74 $\mathrm{mmHg}, 95 \%$ CI 71 to 77 ), but these were not sustained.

\section{Body Weight $(n=1)$}

According to Odnoletkova et al [25], the difference between the groups in favor of telecoaching was a change in body weight of $-1.1 \mathrm{~kg}(P=.004)$.

\section{$\operatorname{BMI}(n=3)$}

In general, all trials noted slight improvements in BMI. Odnoletkova et al [25] and Trief et al [28] reported significant improvements between groups ( $P=.003$ [25] and $P=.021$ [28]), whereas Vasconcelos et al [32] indicated a slight decrease (29.99 $\mathrm{kg} / \mathrm{m}^{2}$ to $\left.29.96 \mathrm{~kg} / \mathrm{m}^{2}\right)$ that was not significant $(P=.764)$.

\section{Cost-Effectiveness $(n=2)$}

"Real-time audio" interventions appear to be moderate in terms of cost-effectiveness (no statistical significances reported). Schechter et al [34] concluded that the costs were moderate relative to the benefits, whereas Varney et al [35] revealed that the cost of a 10-year intervention was covered by the financial savings, with a tendency for health profits.

\section{“Asynchronous" Interventions $(\mathbf{n = 2 8})$}

\section{$\mathrm{HbA}_{1 c}(\mathrm{n}=\mathbf{2 4})$}

Overall, the majority of the studies (all RCTs; 23/34, 96\%) reported apparent improvements. Eleven RCTs reported significant improvements in $\mathrm{HbA}_{1 \mathrm{c}}$ in the intervention groups compared with the control groups $(P<.05)$ [36-46], whereas 3 RCTs showed significant beneficial effects within their intervention groups $(P<.05)$ [47-49]. In addition, 5 RCTs found improvements in the intervention groups compared with matched controls, but the results were not statistically significant $(P>.05)$ [50-54]. Ramadas et al [55], Tildesley et al [38], and Cho et al [56] mentioned significant improvements within their intervention groups $(P=.004$ [55]; real-time continuous glucose monitoring, $P<.001$, versus internet blood glucose monitoring system, $P<.05$ [38]; and $P<.01$ [56]), but the differences between groups were not significant $(P>.05)$.

\section{$\boldsymbol{F B G}(\boldsymbol{n}=2)$}

The studies showed significant improvements in FBG levels in the intervention groups compared with control groups (8.9 $\mathrm{mmol} / \mathrm{L}$, SD $3.9 \mathrm{mmol} / \mathrm{L}$, versus $7.9 \mathrm{mmol} / \mathrm{L}, \mathrm{SD} 2.5 \mathrm{mmol} / \mathrm{L}$, $P=.015$ [55]; and $P=.005$ [46]).

\section{$B P(n=3)$}

In summary, the publications reported apparent improvements in BP. Wild et al [39] found significant improvements in systolic $\mathrm{BP}(P=.017)$ and diastolic BP $(P=.006)$ in the intervention group compared with the control group. Wakefield et al [40] also found a significant decrease in systolic BP in the high-intensity arm of the intervention (home telehealth device with algorithm; $P=.01)$. Fang and Deng [44] found improvements in systolic BP $(P=.069)$ and diastolic BP $(P=.693)$ in the treatment group, but they were not significant.

\section{Body Weight $(n=3)$ and BMI $(n=2)$}

In general, the studies revealed clear beneficial effects of "asynchronous" interventions on both body weight and BMI. For example, Luley et al [41] showed large significant improvements in body weight $(-11.8 \mathrm{~kg}, \mathrm{SD} 8.0 \mathrm{~kg}$; both interand intragroup comparisons with $P=.000)$ and BMI $\left(-4.1 \mathrm{~kg} / \mathrm{m}^{2}\right.$; both intergroup and intragroup comparisons with $P=.00$ ).

\section{HRQoL (n=1)}

No clinically important improvements in HRQoL were seen according to Dario et al [51].

\section{Cost-Effectiveness $(n=1)$}

A weight-loss telemonitoring intervention from Luley et al 2011 [41] showed an effective decline in medication costs of $€ 83$ (US $\$ 101)$ per patient in 6 months.

\section{Time Savings $(n=1)$}

Cho et al [57] showed a significant time savings for physicians of approximately $55 \%$ focusing on patients with $\mathrm{HbA}_{1 \mathrm{c}}$ levels greater than $6.5 \%(P<.05)$.

\section{“Combined" Interventions ( $=\mathbf{3 3})$}

$\boldsymbol{H b A}_{1 c}(\boldsymbol{n}=24)$

In general, most publications $(21 / 24,88 \%)$ reported clear significant improvements in $\mathrm{HbA}_{1 \mathrm{c}}(P<.05)$. Three of these studies were RCTs that achieved significant improvements within their intervention groups $(P<.001$ [58]; $P=.27$ [59]; and $P$ value not reported [60]) but not significant differences between the intervention and control groups $(P>.05)$.

\section{$F B G(n=6)$}

Overall, the studies showed mostly positive effects of "combined" interventions on FBG [58,61-64]. For example, Zhou et al [64] and Jeong et al [58] found significant reductions in FBG levels compared with the control groups $(8.73 \mathrm{mmol} / \mathrm{L}$ to $7.06 \mathrm{mmol} / \mathrm{L}, P<.001$ [64]; and $-12.28 \mathrm{mg} / \mathrm{dL}$, SD 41.20 $\mathrm{mg} / \mathrm{dL}, P=.027$ (telemedicine group [58]).

\section{$B P(n=13)$}

Approximately $85 \%$ (11/13) of the "combined" intervention studies reported beneficial effects on BP [59-61,63-70]. Kempf et al [70] and Crowley et al [65] found significant improvements compared with control groups (systolic BP, $P<.01$ [70]; and systolic BP, $P=.035$, and diastolic BP, $P=.013$ [65]). However, some RCTs noted improvements in their intervention groups (ie, $P<.05$ ) but no significant differences between the groups $(P>.05)$ [60,66-69,71]. Additionally, Kesavadev et al (cohort study with 1000 participants [63]) and Dienstl et al (observational study [61]) indicated similar significant improvements in systolic and diastolic BP $(P<.01$ [63] and $P<.001$ [61]).

\section{Body Weight $(n=7)$}

Most "combination" intervention studies $(5 / 7,71 \%)$ found clear improvements in body weight $[60,61,69,70,72]$. For example, 
Kempf et al [70] reported a significant reduction of 6.2 (SD 4.6) $\mathrm{kg}$ in the intervention group compared with the control group $(-1.0 \mathrm{~kg}$, SD $3.4 \mathrm{~kg} ; P<.01)$.

\section{$B M I(n=9)$}

The majority of publications $(7 / 9,78 \%)$ showed an apparent reduction of BMI. Significant improvements were outlined by 6 studies (intragroup $P=.047$ [59], intragroup $P<.01$ [63], intragroup $P<.001$ [61], intergroup $P=.036$ [73], intergroup $P<.01$ [70], and intergroup $P<.05$ [74]). For example, Kesavadev et al [63] $(\mathrm{n}=1000$ patients $)$ showed a significant reduction of $0.3 \mathrm{~kg} / \mathrm{m}^{2}(P<.01)$ and Kempf et al [70] reported -2.1 (SD 1.5) $\mathrm{kg} / \mathrm{m}^{2}$ in the intervention group versus -0.3 (SD $1.1) \mathrm{kg} / \mathrm{m}^{2}$ in the control group $(P<.01)$.

\section{DRQoL $(n=3)$ and HRQoL $(n=1)$}

All studies found clear improvements in DRQoL and HRQoL. Kempf et al [70] and Nicolucci et al [69] showed significant intergroup improvements in HRQoL $(P<.01$ and $P<.03$, respectively). Jha et al [62] and Dienstl et al [61] (observational studies) reported significant beneficial effects with regard to DRQoL ( $P=.015$ and $P<.001$, respectively).

\section{Cost-Effectiveness $(n=2)$}

Warren et al [75] and Kesavadev et al [63] reported that "combined" interventions are cost-effective. The total costs for the internet-based treatment group were lower than those for the control group (mean US \$3781 versus US \$4662; $P<.001$ [75]). According to Kesavadev et al [63], the extra cost was US $\$ 9.66 /$ month (significance not reported), but money and time saved in physical visits made up for the extra costs.

\section{Time Savings $(n=1)$}

Hsu et al [72] reported great time savings with a cloud-based diabetes management program compared with standard face-to-face care (22.5-minute versus 68.8-minute visit time; significance not reported).

\section{"Combined" Interventions—“Video Clips"Subgroup $(\mathbf{n}=3)$}

\section{$\mathrm{HbA}_{1 c}(\boldsymbol{n}=3)$}

All studies reported significant reductions in $\mathrm{HbA}_{1 \mathrm{c}}$ compared with control subjects $(P<.001$ [76], $P=.005$ [77], and $P=.013$ [78]).

\section{BP and Body Weight $(n=1)$}

Tang et al [76] detected improvements in BP (systolic BP, $P=.306$, and diastolic BP, $P=.374$ ) but no effects on body weight $(P=.232)$.

\section{Short- and Long-Term Effects on $\mathrm{HbA}_{1 \mathrm{c}}$ Values $(\mathrm{n}=41)$ \\ Short- and long-term effects based on the comparison of $\mathrm{HbA}_{1 \mathrm{c}}$ values between the intervention and control groups at the study end points were investigated. Patients' changes in $\mathrm{HbA}_{1 \mathrm{c}}$ from baseline to the end of the study of 41 RCTs are presented in Multimedia Appendix 7.}

\section{“Real-Time Video" Interventions}

A small MA showed that, compared with the control group, 6-month interventions $(n=2)$ were associated with a greater effect size (MD $=-1.15 \%, 95 \% \mathrm{CI}-1.84$ to -0.45$)$ than 12-month interventions $(\mathrm{n}=2)(\mathrm{MD}=-0.6 \%, 95 \% \mathrm{CI}-0.99$ to -0.21$)$.

\section{“Real-Time Audio" Interventions}

The subgroup analysis revealed an effect size, compared to usual care, of $\mathrm{MD}=-0.37 \%$ (95\% CI -0.79 to 0.05 ) for 6-month interventions $(n=3)$ compared with $-0.5 \%$ in the 3 -month intervention [29] and $-0.06 \%$ in the 18 -month intervention [30].

\section{"Asynchronous" Interventions}

The greatest effect was seen in 12-month interventions $(n=2)$ (MD $=-0.77 \%, 95 \% \mathrm{CI}-2.25$ to 0.72 ), followed by 6-month interventions $(\mathrm{n}=8)(\mathrm{MD}=-0.57 \%, 95 \% \mathrm{CI}-0.75$ to -0.39$)$, and 3 -month interventions $(\mathrm{n}=3)(\mathrm{MD}=-0.38 \%, 95 \% \mathrm{CI}-0.54$ to $-0.22)$.

\section{"Combined" Interventions}

The 3-month interventions $(n=5)$ had the greatest effect $(\mathrm{MD}=-0.65 \%, 95 \% \mathrm{CI}-0.98$ to -0.31$)$, whereas 6-month interventions $(\mathrm{n}=7)$ had a slightly smaller effect $(\mathrm{MD}=-0.50 \%$, $95 \% \mathrm{CI}-0.71$ to -0.30 ). In comparison, the effect of 12-month interventions $(\mathrm{n}=4)$ was even smaller $(\mathrm{MD}=-0.25 \%, 95 \% \mathrm{CI}$ -0.73 to 0.24$)$. The subgroup "video clip" interventions $(\mathrm{n}=2)$ showed a reduction of $\mathrm{MD}=-0.23(95 \% \mathrm{CI}-0.23$ to -0.23$)$.

\section{Discussion}

\section{Principal Results}

Telemetry is a viable alternative to usual care for patients with T2DM and can lead to improvements in a wide range of outcomes. The inclusion of evidence from different study designs, such as reviews and trials, in our review strengthens the conclusion that use of telemetric interventions can be feasible in a clinical setting. Other reviews have also recently presented an improvement of clinical outcomes through telemetry and especially a trend toward a reduction in $\mathrm{HbA}_{1 \mathrm{c}}$ levels [16,79]. Our results suggest that telemetry generated clinically meaningful reductions in $\mathrm{HbA}_{1 \mathrm{c}}$ levels. Telemetry has the advantage of helping people who are restricted due to geographic location or a lack of resources [14]. In the time of COVID-19 in particular, the advantages and potential of remote diabetes management becomes even more important.

\section{Impact of Telemetric Interventions on HbA1c}

In general, all types of telemetric interventions clearly improved $\mathrm{HbA}_{1 \mathrm{c}}$. All SRs and MAs also clearly showed that telemetric interventions improve $\mathrm{HbA}_{1 \mathrm{c}}$ specifically, as well as the management of T2DM generally. Furthermore, "real-time video" interventions with a duration of 6 months were the most effective in reducing $\mathrm{HbA}_{1 \mathrm{c}}$. These interventions showed clear improvements in $\mathrm{HbA}_{1 \mathrm{c}}$ levels in patients diagnosed with $\mathrm{T} 2 \mathrm{DM}$ compared to usual care (MD $=-1.15 \%, 95 \% \mathrm{CI}-1.84$ to -0.45$)$. Overall, the effects in the subgroup analysis in terms of the improvement of $\mathrm{HbA}_{1 \mathrm{c}}$ values had MDs between $-1.15 \%$ and $-0.25 \%$. These obvious decreases in $\mathrm{HbA}_{1 \mathrm{c}}$ may indicate a novel 
and additional approach to diabetes care since these therapeutic effects could be accomplished by telemetric intervention alone. However, to optimize glucose homeostasis, individual telemetric approaches may be considered in terms of individual diabetes care as an addition to established therapeutic approaches [4].

\section{Impact of Telemetric Interventions on Main Clinical Outcomes}

Through the use of "combined" interventions, FBG levels improved effectively, which was shown by a moderate number of studies. With "asynchronous" and "real-time audio" interventions, few studies showed an improvement in FBG values. However, the data were inconsistent as to whether "real-time video" interventions reduce FBG effectively.

BP measurements decreased by applying "combined" interventions in a moderate number of the reviewed studies. "Asynchronous" and "real-time audio" interventions also improved BP, but there were comparatively few examinations. Moreover, the study situation for "real-time video" interventions was found to be rather inconsistent.

Body weight decreased in a moderate number of studies by using "combined" interventions effectively. "Real-time audio" interventions also clearly reduced body weight in a few investigations. However, the study situation for "real-time video" interventions was not consistent.

BMI decreased effectively in several studies by using "combined" interventions. The few studies available indicated that "asynchronous" and "real-time audio" interventions decreased BMI. In contrast, the study situation for "real time video" was inconsistent.

Only "combined" interventions showed effective improvements regarding DRQoL and HRQoL, but there were few studies that examined DRQoL and very few studies of HRQoL compared with the other clinical outcomes. "Real-time audio," "asynchronous," and "combined" interventions were potentially cost-effective, but there was only a small number of studies. In addition, "real-time video," "asynchronous," and "combined" interventions occasionally showed time savings, although again, few studies examined these outcomes.

\section{Impact and Comparison of Different Telemetric Interventions}

"Real-time video" interventions did improve $\mathrm{HbA}_{1 \mathrm{c}}$ clearly and effectively in short-term and long-term ways in a large number of studies. Weekly videoconferencing seems to be very effective in terms of reducing $\mathrm{HbA}_{1 \mathrm{c}}$. Due to the heterogeneity of the studies, the results regarding FBG, BP, body weight, BMI, and QoL may be rather inconsistent. However, they all have in common that user-friendly technologies were considered in the development of the interventions and that telemetry was anchored in people's everyday lives, both of which are necessary for optimal results.

"Real-time audio" interventions proved to be effective in reducing $\mathrm{HbA}_{1 \mathrm{c}}$, as demonstrated in numerous studies. Some studies indicated that there is also a clear beneficial impact of these interventions on FBG, BP, body weight, and BMI.
Additionally, "real-time audio" interventions were shown to be cost-effective by the limited studies available.

Furthermore, a large number of studies pointed out that "asynchronous" interventions improved $\mathrm{HbA}_{1 \mathrm{c}}$ effectively. These interventions also improved FBG, BP, and BMI, and showed very positive results in terms of cost-effectiveness and time savings, but few studies using "asynchronous" interventions were available for review.

Most studies assessed "combined" interventions (real-time and asychronous communication). Numerous studies indicated that "combined" interventions improved $\mathrm{HbA}_{1 \mathrm{c}}$ values effectively. Furthermore, a moderate number of interventions had a favorable impact on FBG, BP, BMI, and body weight. In terms of DRQoL and HRQoL, there were few studies to examine these outcomes, but the available studies showed positive tendencies. Additionally, cost-effectiveness and time savings of telemetric interventions showed a positive trend, but sufficient data were lacking.

From our point of view, telemetric T2DM management enhances patient compliance, enables intensive monitoring, and empowers patients to deal with and understand their disease. For a successful implementation of telemetric approaches, it is also essential that the technology is user-friendly, that telemetric T2DM management can be easily integrated into everyday life, and that it is tailored to the patient and his or her life circumstances [24].

Furthermore, we would like to point out that telemetric interventions differ not only in terms of their technologies but also in terms of their contextual focus (eg, nutrition, exercise, etc) and that this aspect should be taken into account when interpreting the results.

\section{Study Limitations}

Although the exclusion criteria were observed, the included studies displayed a wide variation in terms of study design, technical and interventional approaches, duration, and frequency of contact with health care providers (in both the intervention and the control groups), as well as sample size and statistical evaluations used. Due to this heterogeneity, as well as to the small size of our MA, there may be potential for bias. For the same reasons, methodological quality and statistical evaluations could not be carried out. Some studies achieved improvements that were significant within the intervention groups but not between the groups, and methodological weaknesses may have been responsible for that.

\section{Comparison With Prior Work}

Other research groups have displayed similar results. Numerous other SRs and MAs, which were included in this review, reported significant decreases in $\mathrm{HbA}_{1 \mathrm{c}}$ values $(P<.05)$ from the implementation of telemetric interventions [5,11-17]. Su et al [79] examined 55 RCTs and concluded that telemedicine effectively improved clinical outcomes as well as T2DM management compared with usual care. Lee et al [16], who included 4 SRs reporting on 29 studies, concluded that telemetry was a very effective therapeutic approach in terms of decreasing $\mathrm{HbA}_{1 \mathrm{c}}$. According to a review and network MA by Lee et al 
[14], over a 6-month follow-up, telemedicine reduced $\mathrm{HbA}_{1 \mathrm{c}}$ by a mean of $0.43 \%$ (95\% CI $-0.64 \%$ to $-0.21 \%)$. The authors concluded that all telemedical strategies, with the exceptions of telecase management and telementoring, were effective in reducing $\mathrm{HbA}_{1 \mathrm{c}}$ in a clinically meaningful way. Furthermore, Mushcab et al [17] showed that telemonitoring effectively improved $\mathrm{HbA}_{1 \mathrm{c}}$ levels and quality of life. They also observed a high acceptance of web-based systems.

Our research builds on these previous findings, incorporating a large number of studies $(n=99)$, patients $(n=15,939)$, and patient cases $(n=82,436)$ and considering a range of main clinical outcomes in terms of T2DM management. Interestingly, there may be differences in telemetric approaches in terms of T2DM versus type 1 diabetes mellitus management [79], but these still need to be analyzed in more detail.

\section{Conclusions}

To our knowledge, this is the first systematic meta-review analyzing telemetric approaches in T2DM management, including a wide range of important clinical outcomes and technologies.

Viewed together, telemetric interventions clearly improve $\mathrm{HbA}_{1 \mathrm{c}}$ values in the short term and long term specifically and T2DM care generally. Moreover, "real-time video" interventions with a duration of 6 months showed the greatest effect in terms of improving $\mathrm{HbA}_{1 \mathrm{c}}$ values in a sustained way. "Combined" interventions (real-time and asynchronous communication) appeared to be most effective in improving FBG, BP, body weight, BMI, and quality of life.

In conclusion, telemetric interventions clearly improve $\mathrm{HbA}_{1 \mathrm{c}}$ and T2DM management effectively. More studies need to be done, especially with a focus on main clinical outcomes.

\section{Acknowledgments}

This research work was supported by the German Research Foundation (Deutsche Forschungsgemeinschaft, DFG), project number EB 440/4-1. Therefore, the authors would like to thank the DFG for the strong support of this research work.

\section{Conflicts of Interest}

None declared.

\section{Multimedia Appendix 1}

Database search strings.

[PDF File (Adobe PDF File), 417 KB-Multimedia Appendix 1]

\section{Multimedia Appendix 2}

Systematic meta-review search and selection procedure based on PRISMA (Preferred Reporting Items for Systematic Reviews and Meta-Analyses) guidelines.

[PDF File (Adobe PDF File), 525 KB-Multimedia Appendix 2]

\section{Multimedia Appendix 3}

List of included studies.

[PDF File (Adobe PDF File), 362 KB-Multimedia Appendix 3]

\section{Multimedia Appendix 4}

Summary of the studies included in this systematic meta-review.

[PDF File (Adobe PDF File), 872 KB-Multimedia Appendix 4]

\section{Multimedia Appendix 5}

Impact on main clinical outcomes, significant and not significant effects.

[PDF File (Adobe PDF File), 529 KB-Multimedia Appendix 5]

\section{Multimedia Appendix 6}

Significant effects on main clinical outcomes.

[PDF File (Adobe PDF File), 424 KB-Multimedia Appendix 6]

\section{Multimedia Appendix 7}

Changes in glycated hemoglobin (HbA1c) values $(\%)$ in intervention and control groups from baseline to end of the study $(\mathrm{n}=41$ randomized controlled trials). 


\section{Multimedia Appendix 8}

Funnel plot using glycated hemoglobin (HbA1c) based on the randomized controlled trials from the subgroup meta-analysis. [DOCX File, 16 KB-Multimedia Appendix 8]

\section{References}

1. International Diabetes Foundation. IDF Diabetes Atlas 9th edition. 2019. URL: https://www.diabetesatlas.org/en/resources/ [accessed 2020-01-28]

2. American Diabetes Association. 2. Classification and Diagnosis of Diabetes: Standards of Medical Care in Diabetes-2020. Diabetes Care 2020 Jan;43(Suppl 1):S14-S31. [doi: 10.2337/dc20-S002] [Medline: 31862745]

3. American Diabetes Association. 11. Microvascular Complications and Foot Care: Standards of Medical Care in Diabetes-2020. Diabetes Care 2020 Jan;43(Suppl 1):S135-S151. [doi: 10.2337/dc20-S011] [Medline: 31862754]

4. Viigimaa M, Sachinidis A, Toumpourleka M, Koutsampasopoulos K, Alliksoo S, Titma T. Macrovascular Complications of Type 2 Diabetes Mellitus. Curr Vasc Pharmacol 2020;18(2):110-116. [doi: 10.2174/1570161117666190405165151] [Medline: $\underline{30961498]}$

5. Kim Y, Park J, Lee B, Jung C, Park D. Comparative effectiveness of telemonitoring versus usual care for type 2 diabetes: A systematic review and meta-analysis. J Telemed Telecare 2019 Dec;25(10):587-601. [doi: 10.1177/1357633X18782599] [Medline: $\underline{30012042]}$

6. Hanlon P, Daines L, Campbell C, McKinstry B, Weller D, Pinnock H. Telehealth Interventions to Support Self-Management of Long-Term Conditions: A Systematic Metareview of Diabetes, Heart Failure, Asthma, Chronic Obstructive Pulmonary Disease, and Cancer. J Med Internet Res 2017 May 17;19(5):e172 [FREE Full text] [doi: 10.2196/jmir.6688] [Medline: 28526671]

7. American Telemedicine Association. ATA's Standardized Telehealth Terminologyand Policy Language for States on Medical Practice. 2020. URL: https://www.americantelemed.org/wp-content/uploads/2020/10/ ATA-_Medical-Practice-10-5-20.pdf [accessed 2021-01-28]

8. Meister S, Becker S, Leppert F, Drop L. Digital Health, Mobile Health und Co. - Wertschöpfung durch Digitalisierung und Datenverarbeitung. In: Pfannstiel MA, Da-Cruz P, Mehlich H, editors. Digitale Transformation von Dienstleistungen im Gesundheitswesen I. Wiesbaden: Springer Fachmedien Wiesbaden; 2016:185-212.

9. Moher D, Liberati A, Tetzlaff J, Altman DG. Preferred reporting items for systematic reviews and meta-analyses: the PRISMA statement. PLoS Med 2009 Jul 21;6(7):e1000097 [FREE Full text] [doi: 10.1371/journal.pmed.1000097] [Medline: 19621072]

10. McMahon GT, Fonda SJ, Gomes HE, Alexis G, Conlin PR. A randomized comparison of online- and telephone-based care management with internet training alone in adult patients with poorly controlled type 2 diabetes. Diabetes Technol Ther 2012 Nov;14(11):1060-1067 [FREE Full text] [doi: 10.1089/dia.2012.0137] [Medline: 22953754]

11. Huang Z, Tao H, Meng Q, Jing L. Management of endocrine disease. Effects of telecare intervention on glycemic control in type 2 diabetes: a systematic review and meta-analysis of randomized controlled trials. Eur J Endocrinol 2015

Mar;172(3):R93-101 [FREE Full text] [doi: 10.1530/EJE-14-0441] [Medline: 25227131]

12. Cassimatis M, Kavanagh DJ. Effects of type 2 diabetes behavioural telehealth interventions on glycaemic control and adherence: a systematic review. J Telemed Telecare 2012 Dec;18(8):447-450. [doi: 10.1258/jtt.2012.GTH105] [Medline: 23209266]

13. Zhai Y, Zhu W, Cai Y, Sun D, Zhao J. Clinical- and cost-effectiveness of telemedicine in type 2 diabetes mellitus: a systematic review and meta-analysis. Medicine (Baltimore) 2014 Dec;93(28):e312 [FREE Full text] [doi: 10.1097/MD.0000000000000312] [Medline: 25526482]

14. Lee SWH, Chan CKY, Chua SS, Chaiyakunapruk N. Comparative effectiveness of telemedicine strategies on type 2 diabetes management: A systematic review and network meta-analysis. Sci Rep 2017 Oct 04;7(1):12680. [doi: 10.1038/s41598-017-12987-z] [Medline: 28978949]

15. Greenwood DA, Young HM, Quinn CC. Telehealth Remote Monitoring Systematic Review: Structured Self-monitoring of Blood Glucose and Impact on A1C. J Diabetes Sci Technol 2014 Feb 21;8(2):378-389. [doi: 10.1177/1932296813519311] [Medline: 24876591]

16. Lee PA, Greenfield G, Pappas Y. The impact of telehealth remote patient monitoring on glycemic control in type 2 diabetes: a systematic review and meta-analysis of systematic reviews of randomised controlled trials. BMC Health Serv Res 2018 Jun 26;18(1):495 [FREE Full text] [doi: 10.1186/s12913-018-3274-8] [Medline: 29940936]

17. Mushcab H, Kernohan WG, Wallace J, Martin S. Web-Based Remote Monitoring Systems for Self-Managing Type 2 Diabetes: A Systematic Review. Diabetes Technol Ther 2015 Jul;17(7):498-509. [doi: 10.1089/dia.2014.0296] [Medline: 25830528] 
18. Hansen CR, Perrild H, Koefoed BG, Zander M. Video consultations as add-on to standard care among patients with type 2 diabetes not responding to standard regimens: a randomized controlled trial. Eur J Endocrinol 2017 Jun;176(6):727-736. [doi: 10.1530/EJE-16-0811] [Medline: 28325823]

19. Davis RM, Hitch AD, Salaam MM, Herman WH, Zimmer-Galler IE, Mayer-Davis EJ. TeleHealth improves diabetes self-management in an underserved community: diabetes TeleCare. Diabetes Care 2010 Aug;33(8):1712-1717 [FREE Full text] [doi: 10.2337/dc09-1919] [Medline: 20484125]

20. Rasmussen OW, Lauszus FF, Loekke M. Telemedicine compared with standard care in type 2 diabetes mellitus: A randomized trial in an outpatient clinic. J Telemed Telecare 2016 Sep;22(6):363-368. [doi: 10.1177/1357633X15608984] [Medline: 26468213]

21. Toledo FGS, Ruppert K, Huber KA, Siminerio LM. Efficacy of the Telemedicine for Reach, Education, Access, and Treatment (TREAT) model for diabetes care. Diabetes Care 2014 Aug;37(8):e179-e180. [doi: 10.2337/dc13-1909] [Medline: 25061149]

22. Tavsanly NG, Karadakova A, Saygili F. The use of videophone technology (telenursing) in the glycaemic control of diabetic patients: a randomized controlled trial. J Diab Res Clin Met 2013;2(1):1. [doi: 10.7243/2050-0866-2-1]

23. Gordon HS, Solanki P, Bokhour BG, Gopal RK. "I'm Not Feeling Like I'm Part of the Conversation" Patients' Perspectives on Communicating in Clinical Video Telehealth Visits. J Gen Intern Med 2020 Jun;35(6):1751-1758. [doi:

10.1007/s11606-020-05673-w] [Medline: $\underline{\text { 32016705] }}$

24. Carlisle K, Warren R. A qualitative case study of telehealth for in-home monitoring to support the management of type 2 diabetes. J Telemed Telecare 2013 Oct;19(7):372-375. [doi: 10.1177/1357633X13506512] [Medline: 24218347]

25. Odnoletkova I, Goderis G, Nobels F, Fieuws S, Aertgeerts B, Annemans L, et al. Optimizing diabetes control in people with Type 2 diabetes through nurse-led telecoaching. Diabet Med 2016 Jun;33(6):777-785. [doi: 10.1111/dme.13092] [Medline: 26872105]

26. Walker EA, Shmukler C, Ullman R, Blanco E, Scollan-Koliopoulus M, Cohen HW. Results of a successful telephonic intervention to improve diabetes control in urban adults: a randomized trial. Diabetes Care 2011 Jan;34(1):2-7 [FREE Full text] [doi: 10.2337/dc10-1005] [Medline: 21193619]

27. Sarayani A, Mashayekhi M, Nosrati M, Jahangard-Rafsanjani Z, Javadi M, Saadat N, et al. Efficacy of a telephone-based intervention among patients with type-2 diabetes; a randomized controlled trial in pharmacy practice. Int J Clin Pharm 2018 Apr;40(2):345-353. [doi: 10.1007/s11096-018-0593-0] [Medline: 29435911]

28. Trief PM, Fisher L, Sandberg J, Cibula DA, Dimmock J, Hessler DM, et al. Health and Psychosocial Outcomes of a Telephonic Couples Behavior Change Intervention in Patients With Poorly Controlled Type 2 Diabetes: A Randomized Clinical Trial. Diabetes Care 2016 Dec;39(12):2165-2173 [FREE Full text] [doi: 10.2337/dc16-0035] [Medline: 27456837]

29. Maslakpak M, Razmara S, Niazkhani Z. Effects of Face-to-Face and Telephone-Based Family-Oriented Education on Self-Care Behavior and Patient Outcomes in Type 2 Diabetes: A Randomized Controlled Trial. J Diabetes Res 2017;2017:8404328.

30. Blackberry ID, Furler JS, Best JD, Chondros P, Vale M, Walker C, et al. Effectiveness of general practice based, practice nurse led telephone coaching on glycaemic control of type 2 diabetes: the Patient Engagement And Coaching for Health (PEACH) pragmatic cluster randomised controlled trial. BMJ 2013 Sep 18;347:f5272. [doi: 10.1136/bmj.f5272]

31. Benson GA, Sidebottom A, Hayes J, Miedema MD, Boucher J, Vacquier M, et al. Impact of ENHANCED (diEtitiaNs Helping pAtieNts CarE for Diabetes) Telemedicine Randomized Controlled Trial on Diabetes Optimal Care Outcomes in Patients with Type 2 Diabetes. J Acad Nutr Diet 2019 Apr;119(4):585-598. [doi: 10.1016/j.jand.2018.11.013] [Medline: $\underline{30711463}$

32. de Vasconcelos HCA, Lira Neto JCG, de Araújo MFM, Carvalho GCN, de Souza Teixeira CR, de Freitas RWJF, et al. Telecoaching programme for type 2 diabetes control: a randomised clinical trial. Br J Nurs 2018 Oct 18;27(19):1115-1120. [doi: 10.12968/bjon.2018.27.19.1115] [Medline: 30346819]

33. Varney JE, Weiland TJ, Inder WJ, Jelinek GA. Effect of hospital-based telephone coaching on glycaemic control and adherence to management guidelines in type 2 diabetes, a randomised controlled trial. Intern Med J 2014 Sep;44(9):890-897. [doi: 10.1111/imj.12515] [Medline: 24963611]

34. Schechter CB, Walker EA, Ortega FM, Chamany S, Silver LD. Costs and effects of a telephonic diabetes self-management support intervention using health educators. J Diabetes Complications 2016 Mar;30(2):300-305 [FREE Full text] [doi: 10.1016/j.jdiacomp.2015.11.017] [Medline: 26750743]

35. Varney JE, Liew D, Weiland TJ, Inder WJ, Jelinek GA. The cost-effectiveness of hospital-based telephone coaching for people with type 2 diabetes: a 10 year modelling analysis. BMC Health Serv Res 2016 Sep 27;16(1):521 [FREE Full text] [doi: 10.1186/s12913-016-1645-6] [Medline: 27678079]

36. Cho JH, Kim H, Yoo SH, Jung CH, Lee WJ, Park CY, et al. An Internet-based health gateway device for interactive communication and automatic data uploading: Clinical efficacy for type 2 diabetes in a multi-centre trial. J Telemed Telecare 2017 Jul;23(6):595-604. [doi: 10.1177/1357633X16657500] [Medline: 27381040]

37. Egede LE, Williams JS, Voronca DC, Knapp RG, Fernandes JK. Randomized Controlled Trial of Technology-Assisted Case Management in Low Income Adults with Type 2 Diabetes. Diabetes Technol Ther 2017 Aug;19(8):476-482. [doi: 10.1089/dia.2017.0006] [Medline: 28581821] 
38. Tildesley HD, Mazanderani AB, Ross SA. Effect of Internet therapeutic intervention on A1C levels in patients with type 2 diabetes treated with insulin. Diabetes Care 2010 Aug;33(8):1738-1740 [FREE Full text] [doi: 10.2337/dc09-2256] [Medline: 20668152]

39. Wild SH, Hanley J, Lewis SC, McKnight JA, McCloughan LB, Padfield PL, et al. Supported Telemonitoring and Glycemic Control in People with Type 2 Diabetes: The Telescot Diabetes Pragmatic Multicenter Randomized Controlled Trial. PLoS Med 2016 Jul;13(7):e1002098 [FREE Full text] [doi: 10.1371/journal.pmed.1002098] [Medline: 27458809]

40. Wakefield BJ, Holman JE, Ray A, Scherubel M, Adams MR, Hillis SL, et al. Effectiveness of home telehealth in comorbid diabetes and hypertension: a randomized, controlled trial. Telemed J E Health 2011 May;17(4):254-261. [doi: 10.1089/tmj.2010.0176] [Medline: 21476945]

41. Luley C, Blaik A, Reschke K, Klose S, Westphal S. Weight loss in obese patients with type 2 diabetes: effects of telemonitoring plus a diet combination - the Active Body Control (ABC) Program. Diabetes Res Clin Pract 2011 Mar;91(3):286-292. [doi: 10.1016/j.diabres.2010.11.020] [Medline: 21168231]

42. Goodarzi M, Ebrahimzadeh I, Rabi A, Saedipoor B, Jafarabadi MA. Impact of distance education via mobile phone text messaging on knowledge, attitude, practice and self efficacy of patients with type 2 diabetes mellitus in Iran. J Diabetes Metab Disord 2012;11(1):10 [FREE Full text] [doi: 10.1186/2251-6581-11-10] [Medline: 23497632]

43. Lim S, Kang SM, Kim KM, Moon JH, Choi SH, Hwang H, et al. Multifactorial intervention in diabetes care using real-time monitoring and tailored feedback in type 2 diabetes. Acta Diabetol 2016;53(2):189-198. [doi: 10.1007/s00592-015-0754-8] [Medline: 25936739]

44. Fang R, Deng X. Electronic messaging intervention for management of cardiovascular risk factors in type 2 diabetes mellitus: A randomised controlled trial. J Clin Nurs 2018 Feb;27(3-4):612-620. [doi: 10.1111/jocn.13962] [Medline: 28700102]

45. Fortmann AL, Gallo LC, Garcia MI, Taleb M, Euyoque JA, Clark T, et al. Dulce Digital: An mHealth SMS-Based Intervention Improves Glycemic Control in Hispanics With Type 2 Diabetes. Diabetes Care 2017 Oct;40(10):1349-1355. [doi: 10.2337/dc17-0230] [Medline: 28600309]

46. Kim H, Sun C, Yang SJ, Sun L, Li F, Choi IY, et al. Randomized, Open-Label, Parallel Group Study to Evaluate the Effect of Internet-Based Glucose Management System on Subjects with Diabetes in China. Telemed J E Health 2016 Aug;22(8):666-674. [doi: 10.1089/tmj.2015.0170] [Medline: 26938489]

47. Avdal EU, Kizilci S, Demirel N. The effects of web-based diabetes education on diabetes care results: a randomized control study. Comput Inform Nurs 2011 Feb;29(2):101-106. [doi: 10.1097/NCN.0b013e3181fcbdc6] [Medline: 21099675]

48. Cho J, Kwon H, Kim H, Oh J, Yoon K. Effects on diabetes management of a health-care provider mediated, remote coaching system via a PDA-type glucometer and the Internet. J Telemed Telecare 2011;17(7):365-370. [doi: 10.1258/jtt.2011.100913] [Medline: 21933896]

49. Kim S, Kim H. Effectiveness of mobile and internet intervention in patients with obese type 2 diabetes. Int J Med Inform 2008 Jun;77(6):399-404. [doi: 10.1016/j.ijmedinf.2007.07.006] [Medline: 17881285]

50. Lee JY, Chan CKY, Chua SS, Ng CJ, Paraidathathu T, Lee KKC, et al. Telemonitoring and Team-Based Management of Glycemic Control on People with Type 2 Diabetes: a Cluster-Randomized Controlled Trial. J Gen Intern Med 2020 Jan;35(1):87-94. [doi: 10.1007/s11606-019-05316-9] [Medline: 31512187]

51. Dario C, Toffanin R, Calcaterra F, Saccavini C, Stafylas P, Mancin S, et al. Telemonitoring of Type 2 Diabetes Mellitus in Italy. Telemed J E Health 2017;23(2):143-152. [doi: 10.1089/tmj.2015.0224] [Medline: 27379995]

52. Arora S, Peters AL, Burner E, Lam CN, Menchine M. Trial to examine text message-based mHealth in emergency department patients with diabetes (TExT-MED): a randomized controlled trial. Ann Emerg Med 2014 Jun;63(6):745-54.e6. [doi: 10.1016/j.annemergmed.2013.10.012] [Medline: 24225332]

53. Burner E, Lam CN, DeRoss R, Kagawa-Singer M, Menchine M, Arora S. Using Mobile Health to Improve Social Support for Low-Income Latino Patients with Diabetes: A Mixed-Methods Analysis of the Feasibility Trial of TExT-MED + FANS. Diabetes Technol Ther 2018 Dec;20(1):39-48. [doi: 10.1089/dia.2017.0198] [Medline: 29227155]

54. Del Prato S, Nicolucci A, Lovagnini-Scher AC, Turco S, Leotta S, Vespasiani G, ELEONOR Study Group. Telecare Provides comparable efficacy to conventional self-monitored blood glucose in patients with type 2 diabetes titrating one injection of insulin glulisine-the ELEONOR study. Diabetes Technol Ther 2012 Feb;14(2):175-182. [doi: 10.1089/dia.2011.0163] [Medline: 22013886]

55. Ramadas A, Chan CKY, Oldenburg B, Hussein Z, Quek KF. Randomised-controlled trial of a web-based dietary intervention for patients with type 2 diabetes: changes in health cognitions and glycemic control. BMC Public Health 2018 Dec 08;18(1):716 [FREE Full text] [doi: 10.1186/s12889-018-5640-1] [Medline: 29884161]

56. Cho J, Lee H, Lim D, Kwon H, Yoon K. Mobile communication using a mobile phone with a glucometer for glucose control in Type 2 patients with diabetes: as effective as an Internet-based glucose monitoring system. J Telemed Telecare 2009;15(2):77-82. [doi: 10.1258/jtt.2008.080412] [Medline: 19246607]

57. Cho J, Choi Y, Kim H, Lee J, Yoon K. Effectiveness and safety of a glucose data-filtering system with automatic response software to reduce the physician workload in managing type 2 diabetes. J Telemed Telecare 2011;17(5):257-262. [doi: 10.1258/jtt.2011.101006] [Medline: 21628421] 
58. Jeong JY, Jeon J, Bae K, Choi Y, Park K, Kim J, et al. Smart Care Based on Telemonitoring and Telemedicine for Type 2 Diabetes Care: Multi-Center Randomized Controlled Trial. Telemed J E Health 2018 Aug;24(8):604-613. [doi: 10.1089/tmj.2017.0203] [Medline: 29341843]

59. Rodríguez-Idígoras MI, Sepúlveda-Muñoz J, Sánchez-Garrido-Escudero R, Martínez-González JL, Escolar-Castelló JL, Paniagua-Gómez IM, et al. Telemedicine influence on the follow-up of type 2 diabetes patients. Diabetes Technol Ther 2009 Jul;11(7):431-437. [doi: 10.1089/dia.2008.0114] [Medline: 19580356]

60. Pressman AR, Kinoshita L, Kirk S, Barbosa GM, Chou C, Minkoff J. A novel telemonitoring device for improving diabetes control: protocol and results from a randomized clinical trial. Telemed J E Health 2014 Feb;20(2):109-114. [doi: 10.1089/tmj.2013.0157] [Medline: 24404816]

61. Dienstl M, Kempf K, Schulz C, Kruse J, Martin S. Effect of Telemedicine on Glucometabolic Control and Quality of Life in Patients with Type 2 Diabetes Mellitus (in German). Diabetologie und Stoffwechsel 2011 Jun 21;6(03):164-169. [doi: 10.1055/s-0031-1271460]

62. Jha S, Dogra S, Yadav A, Siddiqui S, Panda M, Srivastava K, et al. A prospective observational study to assess the effectiveness of an electronic health (E-health) and mobile health (M-health) platform versus conventional care for the management of diabetes mellitus. Int J Diabetes Dev Ctries 2016 Jun 9;36(4):529-534. [doi: 10.1007/s13410-016-0501-X]

63. Kesavadev J, Shankar A, Pillai PBS, Krishnan G, Jothydev S. Cost-effective use of telemedicine and self-monitoring of blood glucose via Diabetes Tele Management System (DTMS) to achieve target glycosylated hemoglobin values without serious symptomatic hypoglycemia in 1,000 subjects with type 2 diabetes mellitus--a retrospective study. Diabetes Technol Ther 2012 Sep;14(9):772-776. [doi: 10.1089/dia.2012.0088] [Medline: 22734662]

64. Zhou P, Xu L, Liu X, Huang J, Xu W, Chen W. Web-based telemedicine for management of type 2 diabetes through glucose uploads: a randomized controlled trial. Int J Clin Exp Pathol 2014;7(12):8848-8854 [FREE Full text] [Medline: 25674254]

65. Crowley MJ, Edelman D, McAndrew AT, Kistler S, Danus S, Webb JA, et al. Practical Telemedicine for Veterans with Persistently Poor Diabetes Control: A Randomized Pilot Trial. Telemed J E Health 2016 May;22(5):376-384. [doi: 10.1089/tmj.2015.0145] [Medline: 26540163]

66. Liou J, Soon M, Chen C, Huang T, Chen Y, Yeh Y, et al. Shared care combined with telecare improves glycemic control of diabetic patients in a rural underserved community. Telemed J E Health 2014 Feb;20(2):175-178. [doi: 10.1089/tmj.2013.0037] [Medline: 24320193]

67. Wakefield BJ, Koopman RJ, Keplinger LE, Bomar M, Bernt B, Johanning JL, et al. Effect of home telemonitoring on glycemic and blood pressure control in primary care clinic patients with diabetes. Telemed J E Health 2014 Mar;20(3):199-205 [FREE Full text] [doi: 10.1089/tmj.2013.0151] [Medline: 24404819]

68. Stone RA, Rao RH, Sevick MA, Cheng C, Hough LJ, Macpherson DS, et al. Active care management supported by home telemonitoring in veterans with type 2 diabetes: the DiaTel randomized controlled trial. Diabetes Care 2010 Mar;33(3):478-484 [FREE Full text] [doi: 10.2337/dc09-1012] [Medline: 20009091]

69. Nicolucci A, Cercone S, Chiriatti A, Muscas F, Gensini G. A Randomized Trial on Home Telemonitoring for the Management of Metabolic and Cardiovascular Risk in Patients with Type 2 Diabetes. Diabetes Technol Ther 2015 Aug;17(8):563-570. [doi: 10.1089/dia.2014.0355] [Medline: 26154338]

70. Kempf K, Altpeter B, Berger J, Reuß O, Fuchs M, Schneider M, et al. Efficacy of the Telemedical Lifestyle intervention Program TeLiPro in Advanced Stages of Type 2 Diabetes: A Randomized Controlled Trial. Diabetes Care 2017 Dec;40(7):863-871. [doi: 10.2337/dc17-0303] [Medline: 28500214]

71. Stone RA, Sevick MA, Rao RH, Macpherson DS, Cheng C, Kim S, et al. The Diabetes Telemonitoring Study Extension: an exploratory randomized comparison of alternative interventions to maintain glycemic control after withdrawal of diabetes home telemonitoring. J Am Med Inform Assoc 2012;19(6):973-979 [FREE Full text] [doi: 10.1136/amiajnl-2012-000815] [Medline: 22610495]

72. Hsu WC, Lau KHK, Huang R, Ghiloni S, Le H, Gilroy S, et al. Utilization of a Cloud-Based Diabetes Management Program for Insulin Initiation and Titration Enables Collaborative Decision Making Between Healthcare Providers and Patients. Diabetes Technol Ther 2016 Feb;18(2):59-67 [FREE Full text] [doi: 10.1089/dia.2015.0160] [Medline: 26645932]

73. von Storch K, Graaf E, Wunderlich M, Rietz C, Polidori MC, Woopen C. Telemedicine-Assisted Self-Management Program for Type 2 Diabetes Patients. Diabetes Technol Ther 2019 Sep;21(9):514-521. [doi: 10.1089/dia.2019.0056] [Medline: 31287736]

74. Carter EL, Nunlee-Bland G, Callender C. A patient-centric, provider-assisted diabetes telehealth self-management intervention for urban minorities. Perspect Health Inf Manag 2011;8(Winter):1b [FREE Full text] [Medline: 21307985]

75. Warren R, Carlisle K, Mihala G, Scuffham PA. Effects of telemonitoring on glycaemic control and healthcare costs in type 2 diabetes: A randomised controlled trial. J Telemed Telecare 2018;24(9):586-595. [doi: 10.1177/1357633X17723943] [Medline: 28814128]

76. Tang PC, Overhage JM, Chan AS, Brown NL, Aghighi B, Entwistle MP, et al. Online disease management of diabetes: engaging and motivating patients online with enhanced resources-diabetes (EMPOWER-D), a randomized controlled trial. J Am Med Inform Assoc 2013 May 1;20(3):526-534 [FREE Full text] [doi: 10.1136/amiajnl-2012-001263] [Medline: 23171659] 
77. Greenwood DA, Blozis SA, Young HM, Nesbitt TS, Quinn CC. Overcoming Clinical Inertia: A Randomized Clinical Trial of a Telehealth Remote Monitoring Intervention Using Paired Glucose Testing in Adults With Type 2 Diabetes. J Med Internet Res 2015;17(7):e178 [FREE Full text] [doi: 10.2196/jmir.4112] [Medline: 26199142]

78. Steventon A, Bardsley M, Doll H, Tuckey E, Newman SP. Effect of telehealth on glycaemic control: analysis of patients with type 2 diabetes in the Whole Systems Demonstrator cluster randomised trial. BMC Health Serv Res 2014;14:334 [FREE Full text] [doi: 10.1186/1472-6963-14-334] [Medline: 25100190]

79. Su D, Zhou J, Kelley MS, Michaud TL, Siahpush M, Kim J, et al. Does telemedicine improve treatment outcomes for diabetes? A meta-analysis of results from 55 randomized controlled trials. Diabetes Res Clin Pract 2016 Jun;116:136-148. [doi: 10.1016/j.diabres.2016.04.019] [Medline: 27321329]

\author{
Abbreviations \\ BP: blood pressure \\ CT: clinical trial \\ DRQoL: diabetes-related quality of life \\ FBG: fasting blood glucose \\ HbA1c: glycated hemoglobin A1c \\ HRQoL: health-related quality of life \\ IDF: International Diabetes Federation \\ MA: meta-analysis \\ MD: mean difference \\ PRISMA: Preferred Reporting Items for Systematic Reviews and Meta-Analyses \\ RCT: randomized controlled trial \\ SR: systematic review \\ T2DM: type 2 diabetes mellitus
}

Edited by G Eysenbach; submitted 05.08.20; peer-reviewed by D Kim, K Lee, KC Wong; comments to author 21.09.20; revised version
received 13.10.20; accepted 12.12.20; published 17.02.21
Please cite as:
Eberle C, Stichling S
Effect of Telemetric Interventions on Glycated Hemoglobin Alc and Management of Type 2 Diabetes Mellitus: Systematic Meta-Review
JMed Internet Res 2021;23(2):e23252
URL: $\underline{\text { http://www.jmir.org/2021/2/e23252/ }}$
doi: $\underline{10.2196 / 23252}$
PMID: $\underline{33595447}$

CClaudia Eberle, Stefanie Stichling. Originally published in the Journal of Medical Internet Research (http://www.jmir.org), 17.02.2021. This is an open-access article distributed under the terms of the Creative Commons Attribution License (https://creativecommons.org/licenses/by/4.0/), which permits unrestricted use, distribution, and reproduction in any medium, provided the original work, first published in the Journal of Medical Internet Research, is properly cited. The complete bibliographic information, a link to the original publication on http://www.jmir.org/, as well as this copyright and license information must be included. 